\title{
Climatology of precipitation over the Iberian Central System mountain range
}

\author{
L. Durán, ${ }^{\text {a,b,c** }}$ E. Sánchez ${ }^{\mathrm{d}}$ and C. Yagüe \\ a Dpto. Ciencias, Universidad Europea de Madrid, Madrid, Spain \\ b InterMet Sistemas y Redes S.L.U., Madrid, Spain \\ c Dpto. Astrofísica y Ciencias de la Atmósfera, Universidad Complutense de Madrid, Madrid, Spain \\ ${ }^{\mathrm{d}}$ Facultad de Ciencias Medioambientales, Universidad de Castilla la Mancha, Toledo, Spain \\ e Dpto. Geofísica y Meteorología, Universidad Complutense de Madrid, Madrid, Spain
}

\begin{abstract}
An analysis of the observed precipitation for the last 22 years (1989-2010) over Sierra de Guadarrama (centre of Iberian Central System) has been performed. Since this area has received less attention compared with other mountain ranges in Europe and the rest of the world, an exhaustive compilation of literature on precipitation main characteristics on Central Iberia (SW Europe) has been done. The analysis, based on both rain gauges and reanalysis, is focused on the search of the atmospheric mechanisms and moisture sources that lead to precipitation. Also, emphasis has been made in the role played by orography conditioning, the complex spatial patterns observed in the region. This work shows how it behaves as an orographic island that rises over an extensive plateau with a marked Atlantic forcing despite the distance these masses have to travel inlands, with mostly of wet days due to advection of moisture from the ocean and small amount of rain due to local sources of humidity and convective precipitation. It also shows the great enhancement of precipitation caused by the range due to orographic precipitation and the big differences found at the downwind and upwind side of the mountain leading to marked spatial patterns seasonal dependent, complex vertical gradients and high wind direction dependency. Finally, statistically significant mean conditions of variables related with orographic precipitation are given in order to be used as boundary conditions for orographic precipitation modelling exercises. This works gives a climatic framework for future precipitation assessments that could be conducted combining measurements and such models.
\end{abstract}

KEY WORDS moisture advection; orographic precipitation; alpine climate; Iberian Central System; Sierra de Guadarrama

Received 3 January 2012; Revised 22 June 2012; Accepted 9 August 2012

\section{Introduction}

The description of precipitation is a complex and challenging issue for meteorological scientists, due to its irregular nature in space and time, and the diversity of atmospheric scales and processes involved on its description. When the influence of the orography is included on the analysis of precipitation, the problem becomes even more complex. At the same time, precipitation over complex terrain is clearly one of the relevant research areas pointed by the main projects focused on water cycle studies, such as GEWEX (Global Energy and Water cycle Experiment) (Lawford et al., 2004). Complexity is both related to the observational description and the modelling issues. Thus, Lawford et al. (2007), for example, explicitly points to the 'lack of understanding the orographic processes and the best way to incorporate it into models' when dealing with

* Correspondence to: L. Durán, Dpto. Astrofísica y Ciencias de la Atmósfera, Facultad de Ciencias Físicas, Universidad Complutense de Madrid, Avd. Complutense s/n, Madrid 28040, Spain.

E-mail: luis@intermet.es; luisduran@ fis.ucm.es hydrometeorological sciences. While many aspects of the basic mechanisms responsible for orographic precipitation have been understood, important issues remain unresolved (Roe, 2005). Mountainous environments have been described on the Agenda 21 document from United Nations Conference on Environment and Development as a major component of the global environment, being unique areas of the detection of climatic change and the assessment of climate-related impacts (Beniston, 2003).

Several precipitation databases (such as University of Delaware (Matsuura and Willmott, 2009) or CPC (Merged Analysis of Precipitation) (Chen et al., 2008) worldwide, among others), based on surface point observations, are available. For multiple purposes, precipitation has been interpolated into gridded observational databases, in order to be used for climate models validation, hydrology impact assessment, ecology studies and others. Climate Research Unit Database (CRU) (New et al., 1999) is one of the most widely used. They analysed with care what happens on mountainous areas and being cautious and more uncertain on mountainous areas, as they suffer from the complex terrain effect on spatial 
variability, together with the fact of having more scarce and less reliable observations. It is a well-known feature that these databases suffer from undersampling at high elevations (Briggs and Cogley, 1996). A usual approach when dealing with spatial interpolation of rainfall and the effects of complex terrain is the use of digital elevation models along with different statistical procedures, usually multivariate linear regression through different krigging approaches. The basic assumption here is a linear relation with elevation of measured precipitation at the available rain gauge stations (Daly et al., 1994; Goovaerts, 2000; Kyriakidis et al., 2001; Marquínez et al., 2003; Guan et al., 2005). In the last years, a large effort has been done to develop an observational daily gridded database for the whole Europe (Haylock et al., 2008), although it contains a very limited number of stations over the Iberian Peninsula (IP). Herrera et al . (2012) has recently created a high-density daily precipitation database over the peninsular Spain.

It is interesting to notice that several specific numerical models have been developed in the past years to deal with the physical description of how precipitation is affected by the existence of a mountain (Smith and Barstad, 2004; Barstad and Smith, 2005; Barstad et al., 2007; Kirshbaum and Smith, 2008). Their idea is to answer from a physical point of view to the question of how the mountains interact with the flow extracting its humidity and leading to precipitation. Both temporal and spatial scales and their dependency on the environmental conditions of the air masses are analysed on those studies. These orographic precipitation models give more realistic results over very complex terrain but focus on small domains and do not take into account phenomena such as convective storms, which are responsible for considerable rain in certain parts of the globe. It is then crucial to determine the main phenomena that is leading to precipitation in this area, before conducting any kind of modelling exercise. Regarding this, it would be interesting to classify or separate the different types of mechanisms that lead to the precipitation around a mountainous environment: enhancement caused over synoptical frontal structures, purely local orographic modifications on the vertical air movements, or the mesoscale thermal and dynamic effects of mountain sides and valleys. Nevertheless, it has been shown the difficulty in establishing a clear and unambiguous classification of these types of precipitation related to the orography (Little et al., 2008).

Many rainfall analysis from rain gauges measured data and observational campaigns have been carried on in the past years over the main mountainous regions in Western Europe: Frei and Schär (1998), or Bougeault et al . (2001) over the Alps, or López-Moreno et al. (2008) for the Pyrenees, or Romero et al. (1999) over Mediterranean Spain, including part of the Pyrenees. They conclude that precipitation over the IP presents a wide and complex range of different features: from the Atlantic climate on the northern and north-west region, with annual amounts up to $2500 \mathrm{~mm} \mathrm{year}^{-1}$, to the Mediterranean area on the east and south coast of the peninsula. At the south-east coast, there is even a region with semi-arid conditions, with less than $100 \mathrm{~mm}$ year $^{-1}$. The inner part of the IP exhibit an interesting pattern in terms of precipitation, as it is divided by the Central System (CS) mountain range. Both southern and northern plateaus present annual precipitations around $500 \mathrm{~mm}$, but mountains show more than $1000 \mathrm{~mm}$ (Font-Tullot, 1983). Some studies have analysed precipitation climatic features from different perspectives (Esteban-Parra et al., 1998; Martín-Vide, 2004), showing the large spread on the regimes shown in the IP. Del Río et al . (2010) have studied observed trends on precipitation during the last half of the 20th century, showing a negative trend for most of the months and areas of the IP.

Many literature has been produced relating precipitation at IP and large-scale patterns; Zorita et al. (1992) showed how Iberian precipitation is connected with a 'high-index' of the North Atlantic Sea Level Pressure (SLP), confirming that the dominant process responsible for the variability of rainfall over the IP was the intensity of the westerly winds and the frequency of storms embedded in this flow. The North Atlantic Oscillation (NAO) pattern ended to be the main teleconnection pattern in relation with precipitation (RodriguezPuebla et al., 1998; Serrano et al., 1999; Goodess and Jones, 2002; Rodríguez-Fonseca and Serrano, 2002; Muñoz-Díaz and Rodrigo, 2004; Trigo et al., 2004; Gallego et al., 2005; Paredes et al., 2006; López-Bustins et al., 2008; López-Moreno et al., 2011) showing specific aspects related to particular seasons behaviour and the interannual dependency. Zanchettin et al . (2008) also relates winter rainfalls to other variability patterns, such as the (El Niño/Southern Oscillation) ENSO or the Pacific Decadal Oscillation. Climate variability and its relationship with fauna in this specific area has been documented (Bosch et al., 2007).

CS mountain range runs from south-west to north-east right in the centre of the IP, with several peaks rising over $2200 \mathrm{~m}$ over an extensive plateau of $650 \mathrm{~m}$ on average. The central part of this range is known as Sierra de Guadarrama. It is located around $500-600 \mathrm{~km}$ away from the Atlantic coast. This mountainous region can be climatologically defined as an Alpine climate immersed into a Mediterranean continentalized climate (GarcíaRomero et al., 2010). Alpine climates are known to have significant amounts of solid precipitation, low temperatures with small diurnal temperature amplitude, accused synoptic forcing due to the high altitude and strong winds locally influenced by the generalized complex orography. This mountain range has some own features due to be under the continental influence of the extensive and surrounding Castillian plateau, which causes high contrast in temperatures between summer and winter and low precipitation during summer. This continental behaviour is in some way softened by the remaining influence of the Atlantic Ocean and the Mediterranean Sea. These Mediterranean and semi-arid mountain environments behave as humidity islands (López-Moreno et al., 2008). 
Precipitation in the centre of the IP has been related to advection of moist air masses and storms coming from the Atlantic Ocean, which are dried in their way from the north and west to the east and south, losing gradually their water content as they go through the orography (Font-Tullot, 1983). In spring, summer and fall, convective precipitation due to thermal instability is also responsible for some precipitation, but it is very scarce and regionalized compared to total precipitation.

Not much is known about precipitation in CS in terms of temporal and spatial variability. Hydrological records and other studies (Gavilán et al., 1998) show how precipitation is much higher in the higher lands, with isoyets following elevation contour lines (AEMET Atlas, 2011). But the lack of long rain time series with enough spatial coverage have made difficult to keep a reliable assessment of rain fields with enough resolution. Such kind of knowledge would be very relevant as precipitation at these mountains is the only source of fresh water for the inhabitants, agriculture and industry that exist from many centuries ago at both sides of the mountain range. This is especially important in the case of the region of Madrid (capital of Spain), with a population in 2010 of more than 6 million mostly concentrated in the metropolitan area with a huge demand of fresh water fully satisfied by the rivers born at this mountain range.

The drying effect of the mountain when comparing north and south sides can be seen, for example, in terms of the length of the mean dry spells, as shown in Sánchez et al. (2011). There, using both observations and regional climate models (RCM) is seen that dry spells tend to be shorter on the northern lee, and much longer on the southern part, on climatic scales. CS exhibits a clear gradient in terms of the length of consecutive days without rain for the whole of the IP, which adds even another point of interest for a detailed description of its precipitation features.

Most of the previous works on precipitation in the IP usually do not include precipitation records from mountain sites (Rodriguez-Puebla et al ., 1998; Serrano et al ., 1999; Andrés et al., 2000; González-Rouco et al., 2001; Martín-Vide, 2004). This is understandable due to the special behaviour of mountain precipitation and the lack of observations. Using these records would lead them to less representative conclusions and fragmentation of the obtained spatial patterns. Fernandez-Mills (1995), using principal component analysis performed a regionalization of the Spanish precipitation data into ten main clusters including, along with many other stations from all over the Peninsula, one mountain station located in CS (Navacerrada, $1894 \mathrm{~m}$ ). One of the clusters found in the analysis was the North-Western Coast of the Peninsula, which included surprisingly an isolated island in the middle of the plateau, right where the station Navacerrada was located. The lack of more mountainous observational stations prevents from probably a more extended cluster over the CS. A similar behaviour was found by Beranova and Huth (2008), who identified five modes of variability in winter monthly precipitation from mean $500 \mathrm{hPa}$ geopotential height over the Euro-Atlantic sector using stations all over Europe in order to perform a regionalization at an European scale. They used 11 stations in the IP, including Navacerrada station, which ended to be included in the central European cluster, very far away from the immediate Iberian stations which were included in the south-European cluster as expected. There are some studies over other mountain regions of the IP, such as García-Marín et al. (2011), over Penibetica mountains (at southern coast of IP).

Modelled climatic features of precipitation over the IP have been also described using Global Climate Models (GCMs) by many authors, such as Trigo and Palutikof (2001), or by the dynamical downscaling technique of the RCM, focused just over the IP (Arribas et al., 2003; Herrera et al., 2010; Sánchez et al., 2011) or in the frame of an European analysis, begin the IP one of the regions as a whole (Jacob et al., 2007). Due to the enhanced resolution of RCMs compared with GCMs, the precipitation over the mountain regions is clearly improved on the RCMs when compared with the gridded observational databases. López-Moreno et al. (2011) studied the relation of the winter NAO and the mountain areas, including the CS from a group of GCMs, both for observed period and 21st future projections.

The objective of this work is to find simple but robust climatic answers (based on data from the last 20 years of observations) to the following questions about the precipitation at the Iberian Central System: what is the main source of humidity that leads to precipitation, local sources or the ocean? How important is convective (local) precipitation in relation to frontal (larger scales) and orographic precipitation? Is precipitation behaving in the same way at the mountain range and at each of the two slopes? Which role is playing orography: orographic enhancement or rain shadowing? Are rain events spatially fragmented or not by the mountain range? How much solid precipitation is present? The answers to these questions will establish a good foundation for further research necessary for making a reliable assessment of precipitation at this region and will help in the design of new precipitation monitoring systems and appropriate modelling techniques.

\section{Data used}

\subsection{Observational data availability}

There are just few precipitation series from different locations at this mountain range and most of them belong to short-duration-specific campaigns, or are still too short to perform climatological analysis. Conducting meteorological measurements at high altitudes implies many difficulties as sites are very remote, difficult to maintain and with limited power sources (Durán, 2003; Lo et al., 2011). The case is even more complicated when dealing with precipitation, which comes in form of snow and hail during many months of the year. Under these conditions, unheated automatic tipping bucket rain gauges, which 

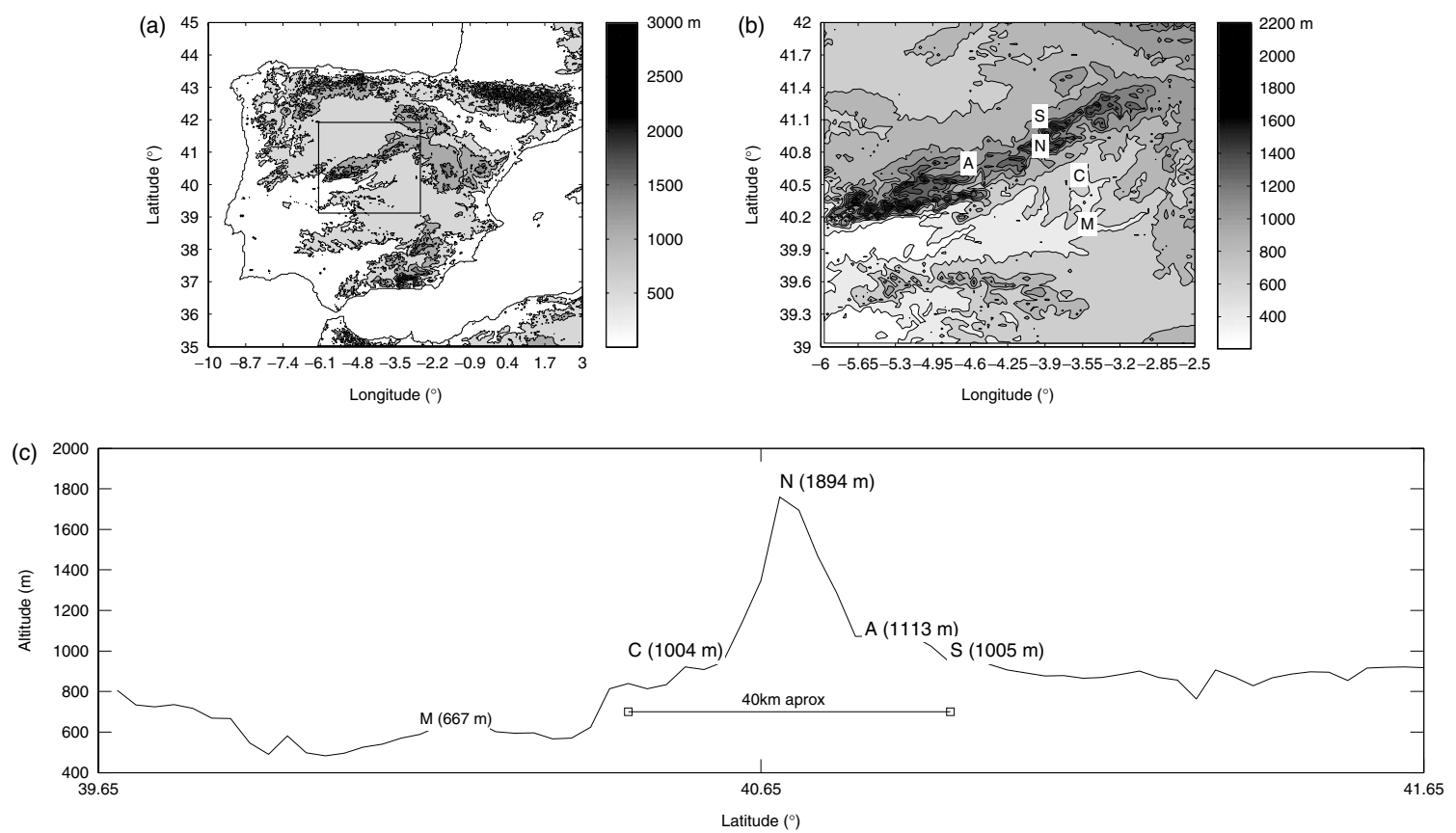

Figure 1. Elevations of Iberian Peninsula (a) and Central System (b) with locations of rain observatories used in this study: Madrid (M), Colmenar Viejo (C), Navacerrada (N), Segovia (S) and Avila (A). An approximate cross section from a trajectory south to north passing close to observatories is also shown (c).

might be appropriate for mostly of locations, are not very reliable for these mountain applications (Sevruk, 1996; Frei and Schär, 1998; Nystuen, 1999). However, manual measurement of precipitation is very useful, since daily maintenance and supervision of the site is done during data collection (WMO, 2008). This eases data validation, a crucial aspect for precipitation studies at mountain sites. It also records the water equivalent of snow and hail, since it is melted for measurement. An obvious disadvantage is that manual measurement is very hand work consuming, what leads to scarce sample points and small spatial coverage.

Fortunately, the Spanish Meteorological Agency (AEMET) have been running a mountain observatory (Navacerrada) located in the heart of Sierra de Guadarrama, since 1946. During this period, manual observations of the main meteorological variables have been collected by the Agency staff following World Meteorological Organization (WMO) standards every $6 \mathrm{~h}$. There are some other observatories with historical records and good measurement practises in Madrid (since 1920), Colmenar Viejo (since 1978), Segovia (since 1989) and Avila (since 1985). Only Navacerrada observatory $(\mathrm{N})$ can be considered a mountain observatory. Colmenar (C) and Segovia are located at the southern and northern side of the mountain range, and Avila (A) and Madrid (M) are located at the northern and southern plateau, at a considerable distance. Geographical location of the observatories is shown in Figure 1.

Data is available for all the stations after 1989, so the period from 1989 to 2010 has been chosen for this study. Twenty-two years of daily data should be enough for a climatic analysis of this kind.

\subsection{ERA interim reanalysis}

To describe and analyse the synoptic conditions and their relationship with precipitation at the five sites, the ECMWF ERA interim Re-Analysis will be used, which is the improved reanalysis in terms of data assimilation, improved physics, biases corrections and increased horizontal resolution compared with the classical ERA40 database (Uppala et al., 2008). This reanalysis is the same time period as for the stations is chosen, with a $1.5^{\circ}$ horizontal resolution. Surface variables are: $2 \mathrm{~m}$ air temperature and SLP; and 23 atmospheric levels from surface up to $200 \mathrm{hPa}$ : U and V components of wind, geopotential height, specific humidity. The domain of study for the reanalysis is taken from $48^{\circ} \mathrm{N}$ to $33^{\circ} \mathrm{N}$ in latitude and $15^{\circ} \mathrm{W}$ to $1.5^{\circ} \mathrm{E}$ in longitude.

\section{Results}

\subsection{Main climatic characteristics}

An Alexandersson homogeneity test (Alexandersson, 1986) has been performed using Madrid (Retiro) observatory as the reference station, since this observatory has been shown to be homogeneous (Gonzalez-Rouco et al., 2001). Figure 2 shows the test statistic ' $T$ ' obtained for the rest of the observatories. As the critical value for rejecting the null hypothesis that the series are homogeneous at a $5 \%$ confidence level for 22 samples is 7 , then it can be concluded that the series are homogeneous.

In Table I, the main annual statistics for the whole period (1989-2010) are presented. As expected, the mean precipitation is much higher over the mountainous station (N), with 1229 mm year $^{-1}$, meanwhile, the rest of the 


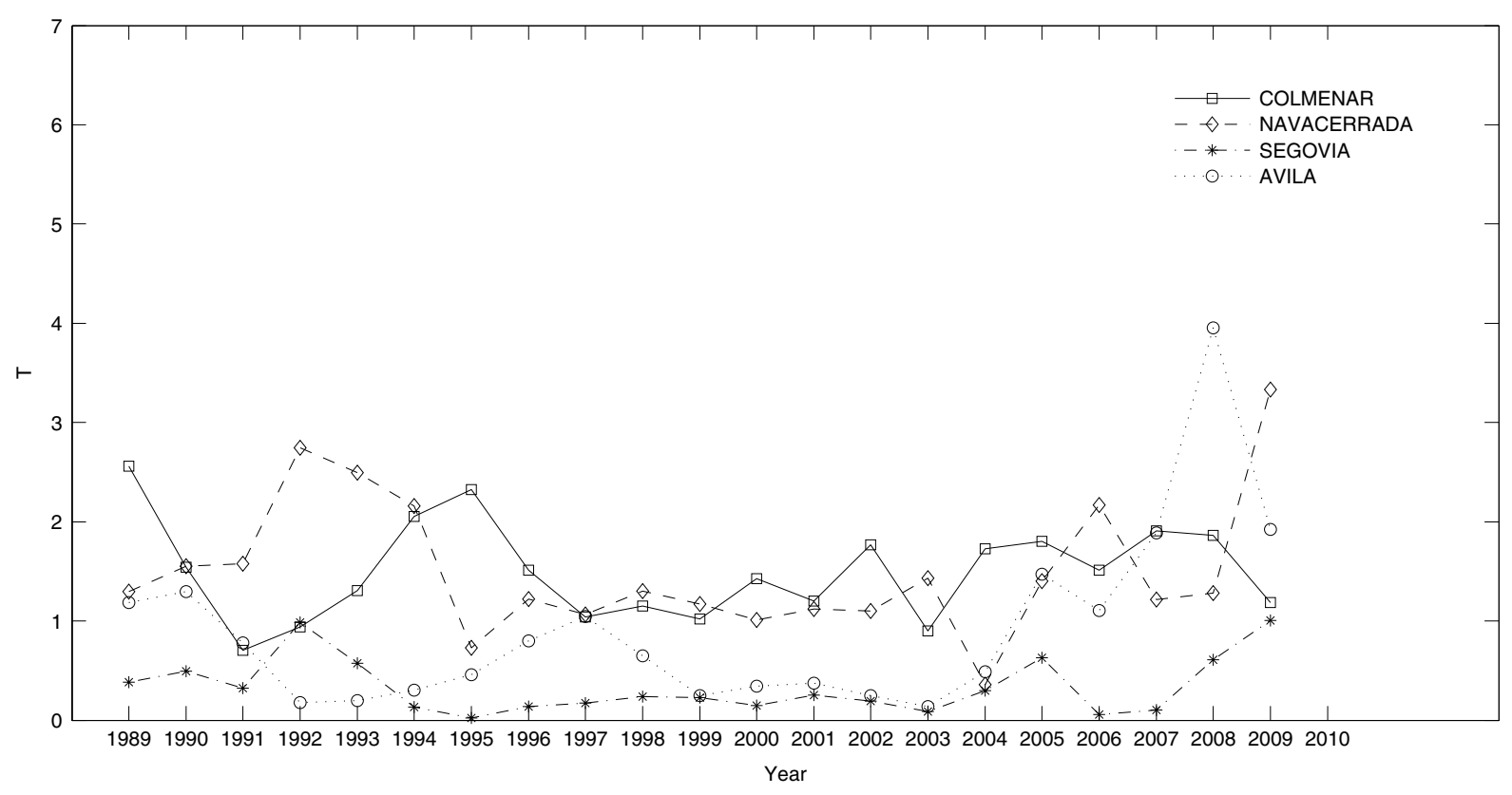

Figure 2. Values of $T$ of an Alexandersson test for Colmenar, Navacerrada, Segovia and Avila using Madrid as reference station. The critical $T$ value for $5 \%$ confidence level and 22 samples is 7 .

Table I. Annual basic statistics per observatory (1989-2010).

\begin{tabular}{lcccrr}
\hline & Madrid & Colmenar & Navacerrada & Segovia & Avila \\
\hline Mean (mm) & 427 & 567 & 1229 & 479 & 418 \\
Median (mm) & 435 & 535 & 1160 & 451 & 401 \\
Standard deviation (mm) & 96 & 158 & 301 & 102 & 108 \\
Maximum (mm) & 573 & 859 & 2011 & 812 & 679 \\
Minimum (mm) & 252 & 354 & 806 & 352 & 243 \\
Mean winter precipitation (DJF, \%) & 28 & 30 & 27 & 24 & 23 \\
Mean spring precipitation (MAM, \%) & 28 & 26 & 9 & 17 & 14 \\
Mean summer precipitation (JJA, \%) & 9 & 34 & 33 & 30 & 33 \\
Mean fall precipitation (SON, \%) & 35 & 34 & & & 29 \\
\hline
\end{tabular}

observatories show values smaller than 600 mm year $^{-1}$. Mountainous station also exhibits larger spread from year to year $\left(300 \mathrm{~mm} \mathrm{year}^{-1}\right)$, in comparison with the plateau observatories (less than $150 \mathrm{mmyear}^{-1}$ ). Table I also shows the percentage for each of the seasons, with around a $30 \%$ for spring, winter and autumn, meanwhile summer only gives around $10 \%$ of the total annual amount. It is remarkable how Avila and Segovia show higher summer values than the rest.

Figure 3(a) shows the climatic annual cycle of precipitation at the five observatories, who all show bimodal patterns with wet seasons in spring and fall plus winter and an accused minimum in summer. Precipitation at site $\mathrm{N}$ is always considerable higher than the other stations, as expected due to elevation, with an important percentage of solid precipitation (Figure 4). It is important to mention how precipitation shows a very marked decrease from June to September for all observatories. This behaviour is characteristic of the Mediterranean climates that dominate most of the IP. Here it is shown how CS alpine climate seems also to be influenced by such annual precipitation cycle, resulting in a larger decrease of precipitation during summer than other Alpine-like regions (Frei and Schär, 1998). This marked difference between summer and the rest of the year might be caused by the decrease of the advection of humidity from the ocean due to synoptic disturbances. Along with this, orographically induced convective storms might be less frequent compared with other mountain chains, probably due to the lack of local sources of humidity at the northern and southern plateau. It is also remarkable how this summer minimum starts later in the northern side observatories $\mathrm{A}$ and $\mathrm{S}$, that show considerable precipitation in June.

Maximum precipitation is found in spring in northern side and in fall in southern side. It is also shown how precipitation during summer months is closer at all sites, which might indicate a possible decrease in the role of orography in the production or enhancement of precipitation during this season, probably due to the convective origin of precipitation during these months. Regarding $\mathrm{N}$ site, precipitation is always considerably higher than others, with a shorter summer drought which extends only from July to August. Precipitation at 

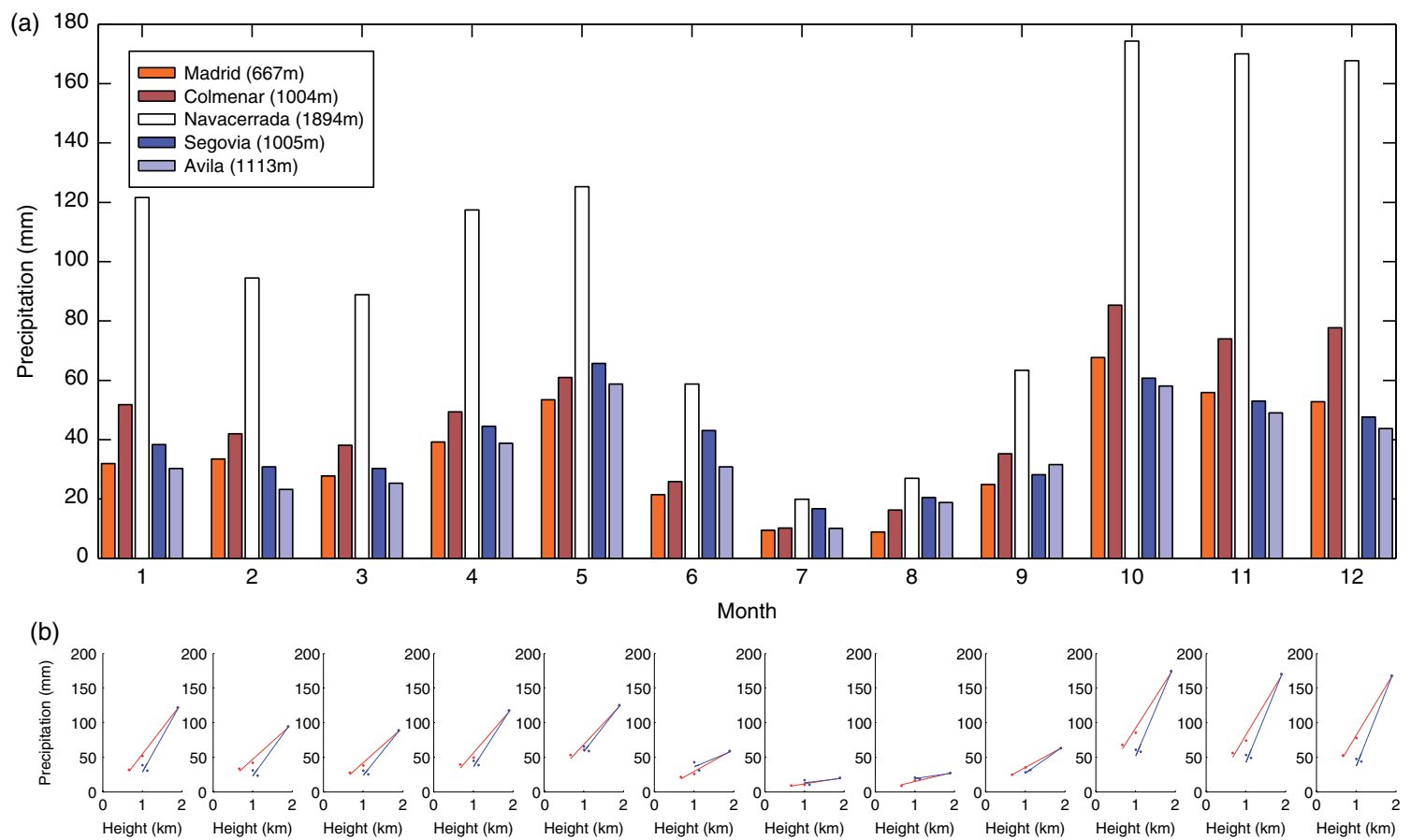

Figure 3. (a) Mean monthly precipitation at the observatories for period 1989-2010. (b) Mean monthly precipitation altitude gradients for south side of range (red) and north side of range (blue). Navacerrada observatory is shared for both sides calculation. Bars follow the same order than legend.

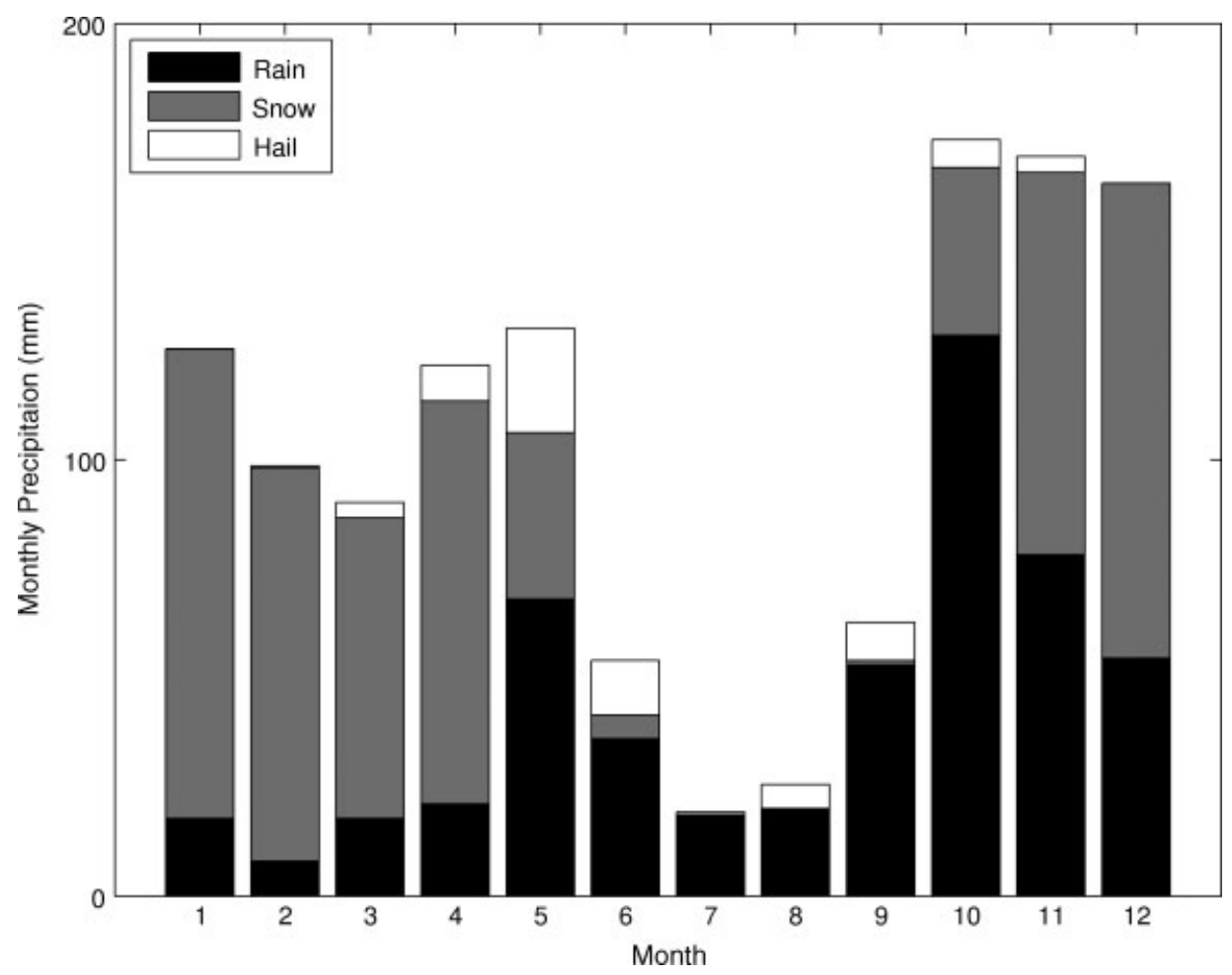

Figure 4. Rain, snow and hail precipitation at highest observatory (Navacerrada).

$\mathrm{N}$ seems to be the result of the phenomena that affects both sides of the range along with its own orographic processes.

Figure 3(b) shows the vertical linear precipitation gradient calculated for every month and for southern and northern side of the range ( $\mathrm{N}$ observatory is shared for both sides calculation). These gradients would be useful for calculating a simple monthly precipitation atlas of the region using a digital elevation model (Daly et al., 1994). Here it is calculated just to show differences between southern and northern side, and the special behaviour of June. 


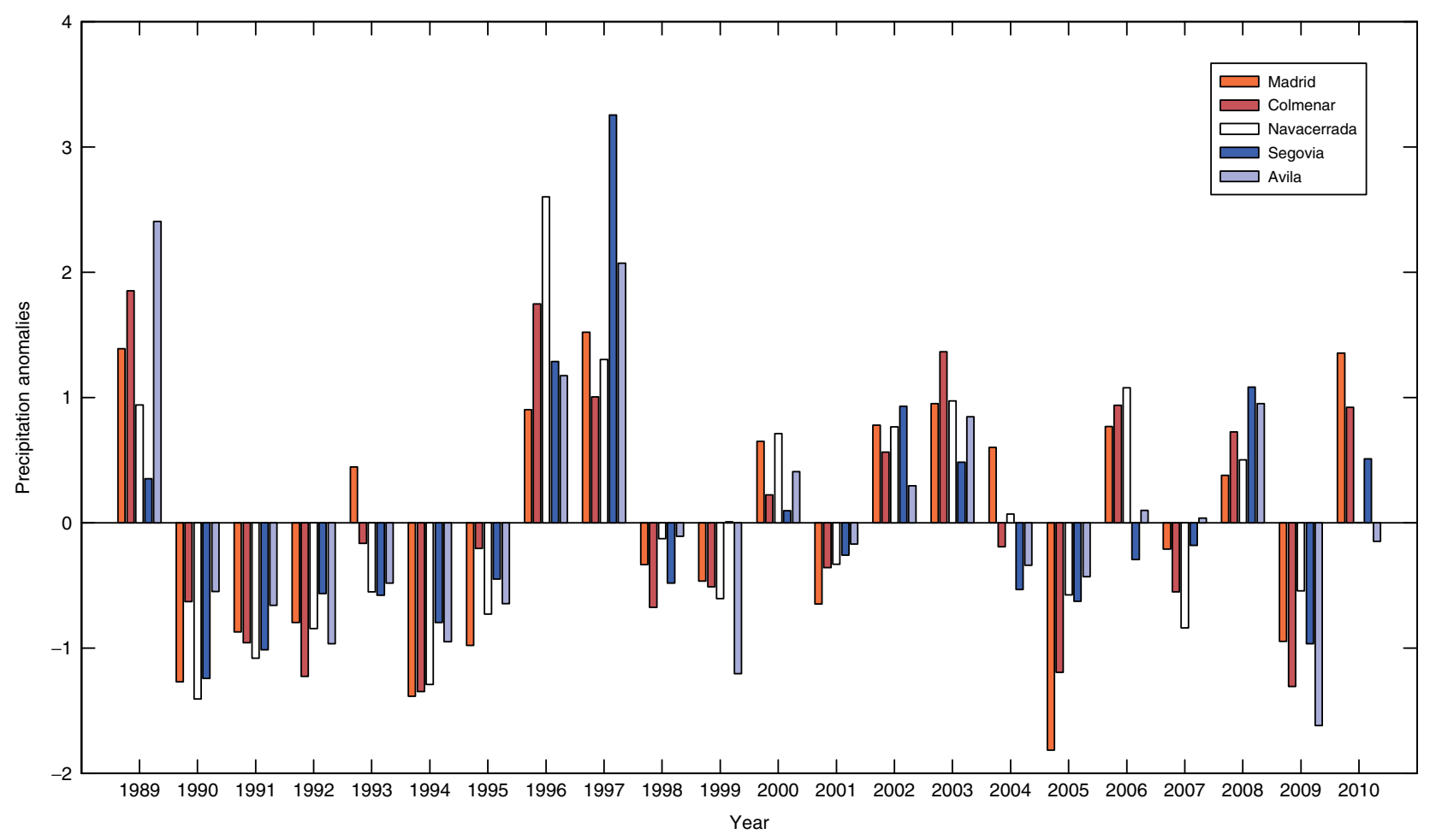

Figure 5. Annual standardized precipitation anomalies for the observatories. Anomalies are calculated by subtracting the annual mean to every year total precipitation and then divided by standard deviation for the period 1989-2010. Bars follow the same order than legend.

Figure 5 shows the time series anomalies, related to the annual climatology, at each of the five observatories, calculated as the annual mean precipitation minus the whole period mean divided by the standard deviation for the whole period. It is shown how precipitation in CS shows the well-known 1990s persistent dry anomaly and the shift in 1996 that affected the whole Peninsula. This feature has been documented in previous works in relation with changes in the tropical North Atlantic Sea Surface Temperature (Rodríguez-Fonseca and Castro, 2002; Rodríguez-Fonseca et al., 2006; Losada et al., 2007). It is important to mention that larger anomalies at each observatory are reached at different years, indicating again how large-scale phenomena have different impact on precipitation at each side and top of mountain.
Table II shows the results of $T$-test on the monthly averages of all possible combinations of pairs of observatories. If marked, the sample means belong to different populations with a $5 \%$ significance level. It is shown how during mostly of the year, mean precipitation at $\mathrm{N}$ is significantly different compared to any of the other stations. However, all non-mountainous observatories show equal means except for some months: June, August and February. Important to mention is how Madrid and Colmenar show significant equal means for all year round. The same happens between Avila and Segovia. This fact is used to simplify the analysis to observatories $\mathrm{S}, \mathrm{N}$ and C. S would be representative of the northern side of the $\mathrm{SC}, \mathrm{N}$ representative of the mountain range and $\mathrm{C}$ representative of the southern side.

Table II. Results of $T$-test on the monthly averages. If marked, the sample means values come from different populations with a $5 \%$ significance level.

\begin{tabular}{|c|c|c|c|c|c|c|c|c|c|c|c|c|}
\hline Sites/Month & 1 & 2 & 3 & 4 & 5 & 6 & 7 & 8 & 9 & 10 & 11 & 12 \\
\hline \multicolumn{13}{|l|}{ Madrid-Colmenar } \\
\hline Madrid-Navacerrada & $\mathrm{X}$ & $\mathrm{X}$ & $X$ & $\mathrm{X}$ & $X$ & $\mathrm{X}$ & $\mathrm{X}$ & $\mathrm{X}$ & $\mathrm{X}$ & $\mathrm{X}$ & $\mathrm{X}$ & $\mathrm{X}$ \\
\hline Madrid-Segovia & & & & & & $X$ & & $\mathrm{X}$ & & & & \\
\hline Madrid-Avila & & & & & & & & $\mathrm{X}$ & & & & \\
\hline Colmenar-Navacerrada & $\mathrm{X}$ & $\mathrm{X}$ & $\mathrm{X}$ & $\mathrm{X}$ & $\mathrm{X}$ & $X$ & $\mathrm{X}$ & & $\mathrm{X}$ & $\mathrm{X}$ & $\mathrm{X}$ & $\mathrm{X}$ \\
\hline Colmenar-Segovia & & & & & & $X$ & & & & & & \\
\hline Colmenar-Avila & & $\mathrm{X}$ & & & & & & & & & & \\
\hline Navacerrada-Segovia & $X$ & $\mathrm{X}$ & $\mathrm{X}$ & $\mathrm{X}$ & $\mathrm{X}$ & & & & $\mathrm{X}$ & $\mathrm{X}$ & $\mathrm{X}$ & $\mathrm{X}$ \\
\hline Navacerrada-Avila & $X$ & $\mathrm{X}$ & $\mathrm{X}$ & $X$ & $\mathrm{X}$ & $X$ & & & $\mathrm{X}$ & $\mathrm{X}$ & $\mathrm{X}$ & $\mathrm{X}$ \\
\hline Segovia-Avila & & & & & & & & & & & & \\
\hline
\end{tabular}


Table III. Definition of spatial precipitation classes according to the observatories that record simultaneously daily precipitation.

\begin{tabular}{lccc}
\hline Pattern & Rain at $\mathrm{S}$ & Rain at $\mathrm{N}$ & Rain at C \\
\hline SNC & YES & YES & YES \\
SNo & YES & YES & NO \\
oNC & NO & YES & YES \\
oNo & NO & YES & NO \\
Soo & YES & NO & NO \\
ooC & NO & NO & YES \\
SoC & YES & NO & YES \\
ooo & NO & NO & NO \\
\hline
\end{tabular}

In such complex orography, density of stations would not be enough to perform a spatial interpolation as done by other authors (Daly et al., 1994; Frei and Schär, 1998; Kyriakidis et al., 2001; Marquínez et al., 2003; Guan et $a l ., 2005)$. Nevertheless, in order to have an idea of the spatial extent of the rain episodes, eight different spatial precipitation sizes are defined using precipitation from $\mathrm{S}$, $\mathrm{N}$ and $\mathrm{C}$; considering all the possible combinations of wet and dry days at each observatory (wet day is defined as a day with a precipitation higher than $0.1 \mathrm{~mm} \mathrm{~d}^{-1}$ ). Classes are shown in Table III. Each of these classes represent the minimum known size of the rain event. For example, a day classified as 'SNC' would mean that rain was observed that day at the three observatories: S, N and $\mathrm{C}$. Not much is known about the exact precipitation field, but at least it is sure that daily rain field has a minimum size equal to the distance from $\mathrm{S}$ to $\mathrm{C}$. Results using this classification are shown in Figure 6 for each season. Around half of the days during winter, spring and fall are wet days (rain at least at one of the three sites: all patterns but 'ooo') in $C S$. Of these wet days, only half of them, rain falls simultaneously at the three sites (SNC). The rest of wet days, rain falls at only two sites or one site. When rain falls at only two sites, these sites are adjacent. Except in summer, with just $37 \%$ of occurrence, broad rain pattern (SNC) becomes the most frequent pattern being around $50 \%$ of all the wet days. The second most frequent pattern, except in summer, is rain only at the top of the mountain and at northern side of the range ('SNo'), followed very closely in frequency by rain only on the top of the mountain ('oNo'), with an almost constant frequency all the year round. North side and top pattern ('SNo') is more frequent than South side and top pattern ('oNC'). Considering that monthly rain means (Figure 2) are higher during winter, half spring and fall in the southern side, rain episodes are less frequent in the South side but with higher amounts. Rain at only one side of the range ('Soo' or 'ooC') is very infrequent, except in summer. These wet days, without rain on the top of the mountain, might be associated to local convective storms, that can be related to temperature changes associated to mountain conditions. Frequency of rain at both sides of the mountain but with no rain on the top ('SoC'), is almost negligible, confirming the consistency of this simple classification. This pattern classification is also dependent on the direction of the fronts that arrive to the CS, as it will be shown on next paragraph.

3.2. Relationship between precipitation and humid air masses reaching Sierra de Guadarrama

Precipitation is the result of a set of conditions in the atmosphere that lead the water vapour to condense and form droplets (clouds) that eventually reach the ground. Sometimes these conditions are reached in a very short time and space, like thermally induced storms, but in others these conditions depend in the state of a very large portion of the atmosphere with an origin of hundreds of kilometers away from where precipitation takes place. These are known as the synoptic conditions.

Advection of humid air masses over continents is an essential source of precipitation at extra-tropical latitudes. One way to analyse advection of humid air masses consists of studying the flux of water vapour in the atmosphere (Rasmuson, 1968; Trenberth and Guillemot, 1998; Mariotti and Struglia, 2002). Specific humidity and wind velocity integrated from surface to $200 \mathrm{hPa}$ levels have been used to calculate horizontal total column water vapour flux (hereafter TCWVF) using Equations (1) and (2).

$$
\begin{aligned}
& \overline{Q_{u}}=\frac{1}{g} \int_{p_{u}}^{p_{s}} q u d p \\
& \overline{Q_{v}}=\frac{1}{g} \int_{p_{u}}^{p_{s}} q v d p \\
& \bar{Q}=\overline{Q_{u}} i+\overline{Q_{v}} j
\end{aligned}
$$

where $p_{s}$ is surface pressure and $p_{u}$ is $200 \mathrm{hPa}, \mathrm{q}$ is moisture, $u$ and $v$ are the horizontal wind components and thus $\bar{Q}$ is total column of water vapour flux.

Figure 7 shows the Pearson linear correlation coefficients between the monthly precipitation anomalies at the three observatories and monthly TCWVF anomalies for each grid point in order to analyse the relationships between moisture advection and precipitation at the CS. Not significant correlations are neglected after applying a Student's $t$-test with $95 \%$ confidence level and monthly anomalies of TCWVF at every grid point and precipitation anomalies at the observatories have been calculated. Anomalies are computed subtracting to the monthly value at each particular year, the climatological monthly mean, dividing the result by the climatological standard deviation (These are known as standardized anomalies). It is noticeable that the great correlation found between TCWVF values and precipitation anomalies at the three observatories for all year around except summer. Correlation maps for $\mathrm{S}$ show positive values during mostly of the year, indicating that an anomalous higher flux of water vapour into IP is connected to an anomalous increase of precipitation. Maximum is located in the southern part of IP, this only indicates that the anomalies of TCWVF at that grid point are highly correlated with precipitation 

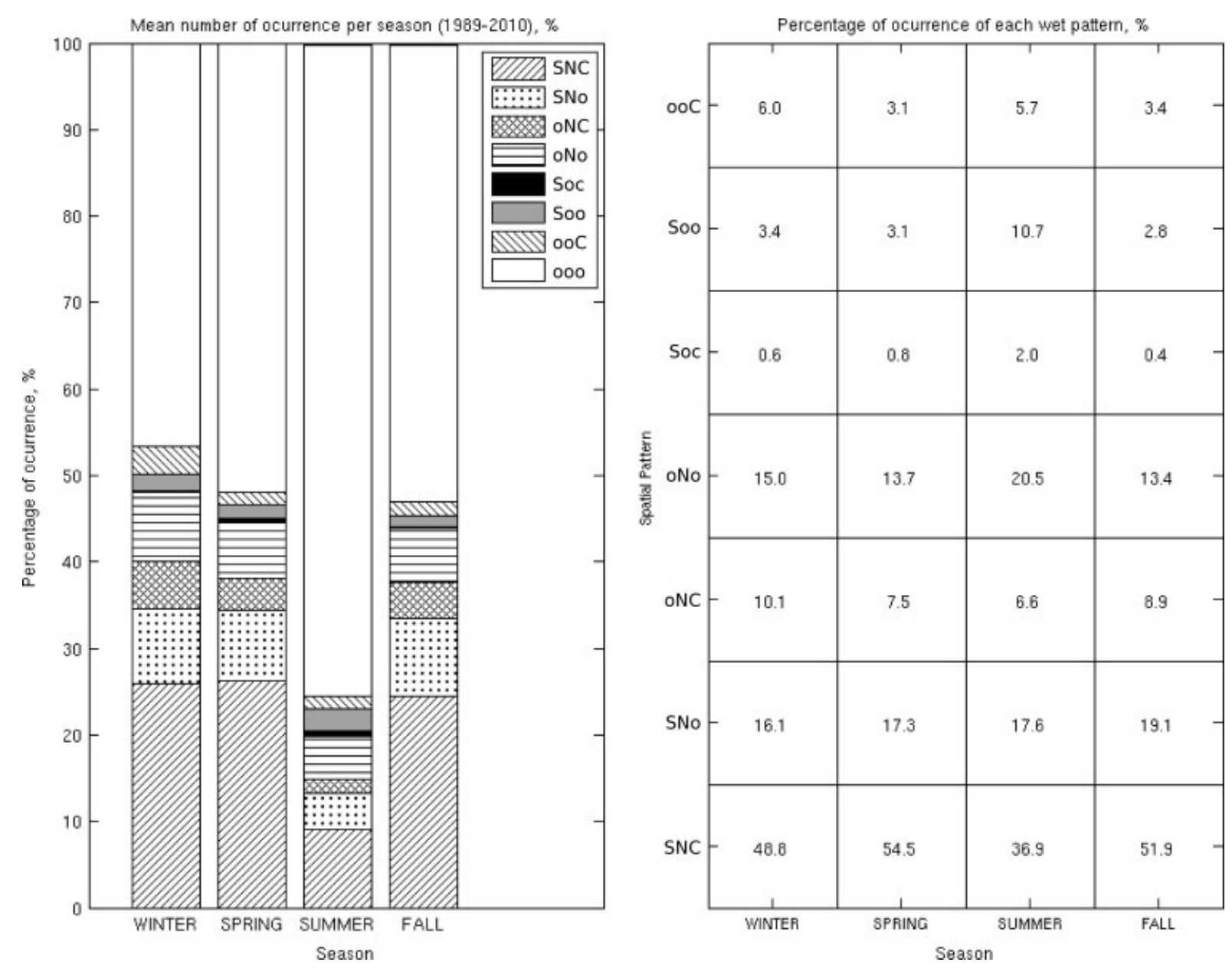

Figure 6. Spatial precipitation patterns frequencies (left) and spatial precipitation patterns frequencies for wet days (right).
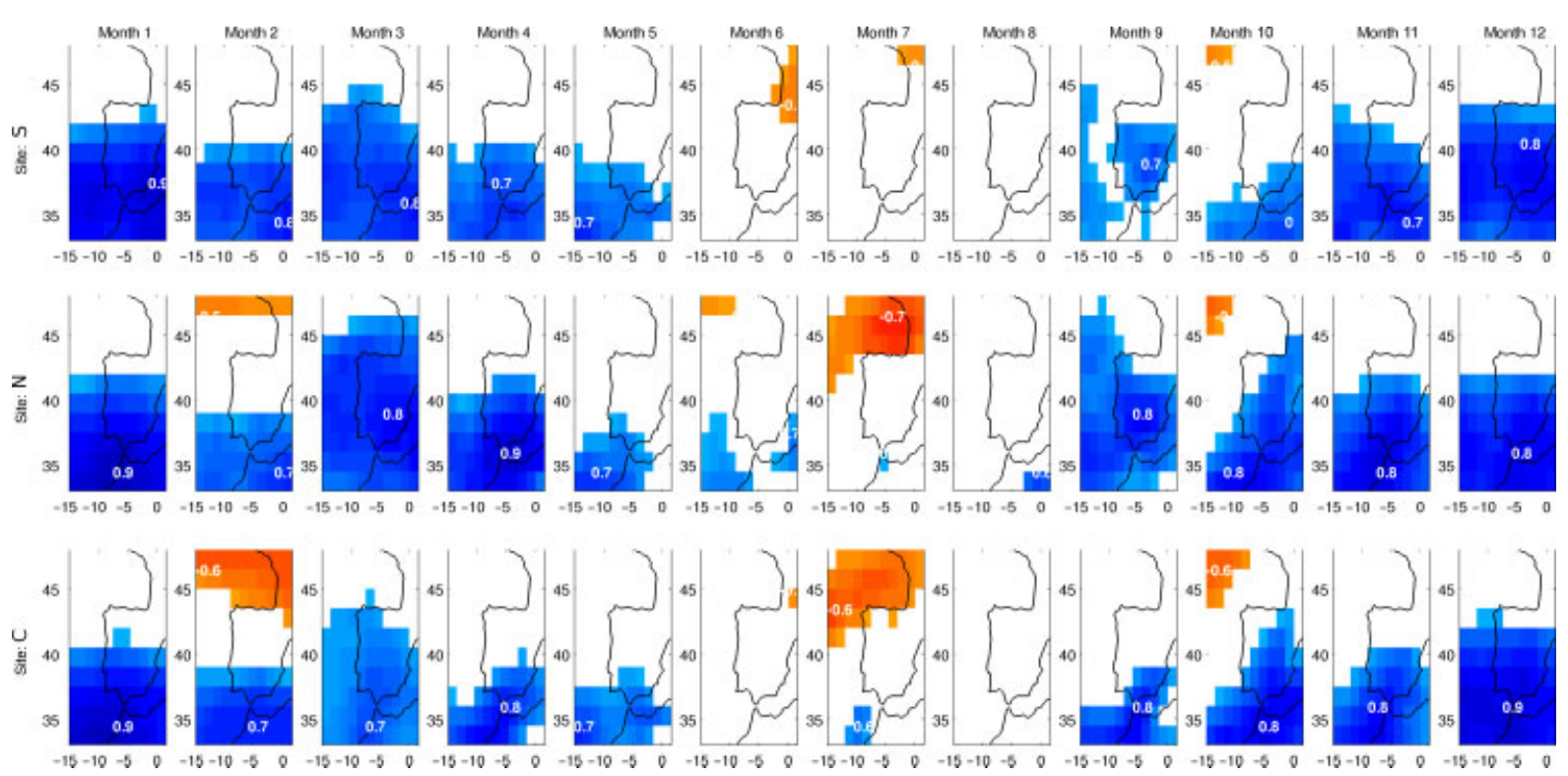

Figure 7. Pearson correlation coefficient maps between monthly TCWVF anomalies at each grid point and monthly precipitation anomalies at northern side observatory (S), mountain top (N) and southern side observatory (C). Only significant correlations are shown. 

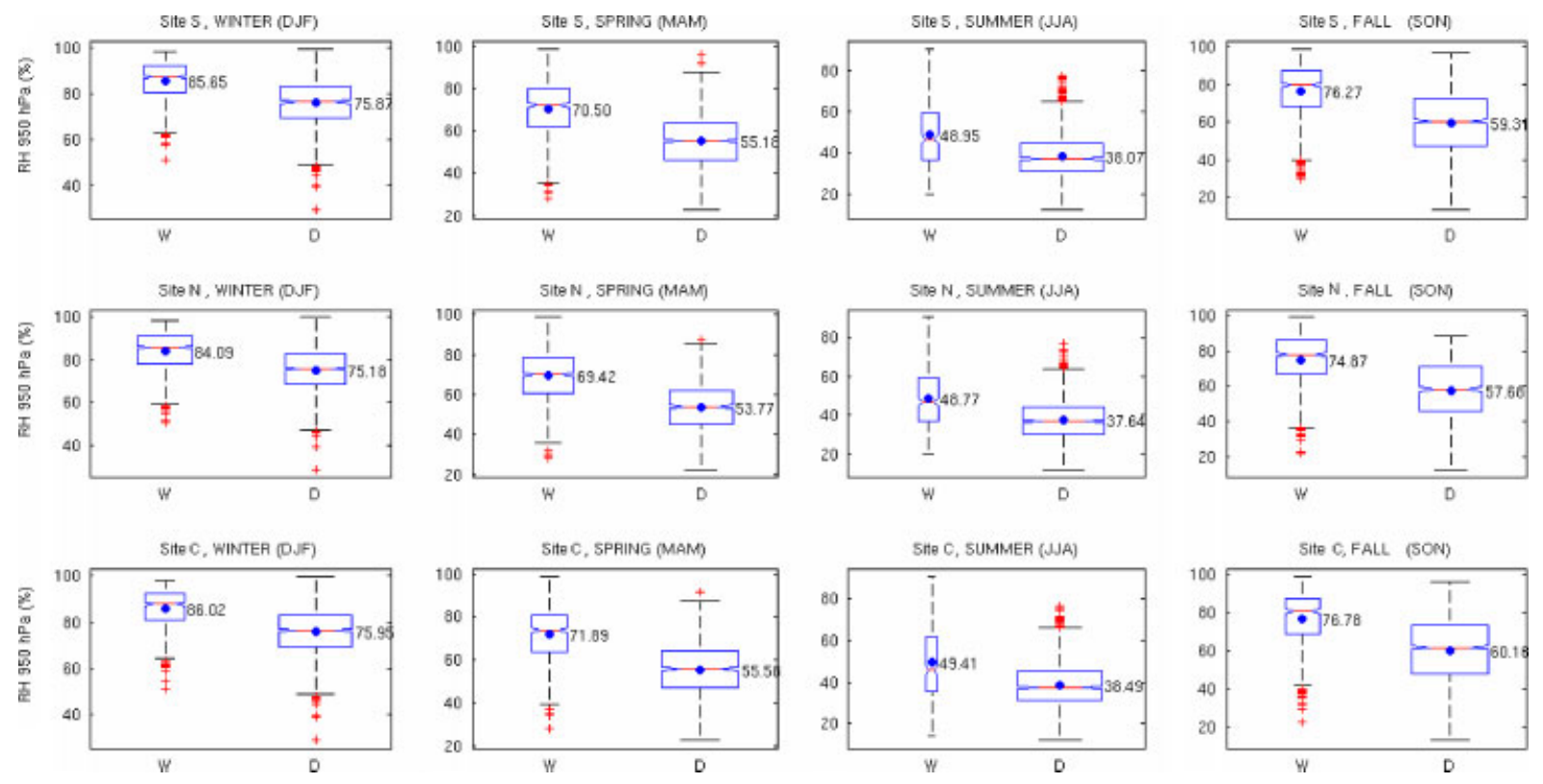

Figure 8 . Box plot of relative humidity at $950 \mathrm{hPa}$ and precipitation for all sites and seasons.

anomalies, what would be a good predictor, but does not give any physical cause-effect connection. These anomalies might be associated with the main teleconnection pattern affecting IP, like NAO and others (Rodriguez-Puebla et al., 1998; Serrano et al., 1999; Goodess and Jones, 2002; Rodríguez-Fonseca and Serrano, 2002; MuñozDíaz and Rodrigo, 2004; Trigo et al., 2004; Gallego et al., 2005). Southern observatory behaves slightly different. Here, correlation maps are shifted to the south and first a dipole pattern is shown in February, July and October. These dipole patterns are formed when a band shape flux is shifted to the south parallel to its initial trajectory, leaving northern part with a deficit in relation with climatology and an increase in the southern part. Mountain observatory shares behaviour with $\mathrm{S}$ at the beginning of summer but does it with $\mathrm{N}$ for the end of summer. It seems very interesting the high negative values found in July. All these results confirms the important Atlantic forcing affecting CS. TCWVF seem to be reaching IP with a great variety of shapes leading to a complex flow as a result of the daily synoptic configuration.

3.3. Average atmospheric conditions of the air masses that lead to precipitation in CS

An added value of having the reanalysis data is that it is possible to analyse the mean conditions of the advected air masses before they reach the mountain range and before orographic precipitation processes dry the air. To understand the conditions of these masses the following variables are analysed upwind the mountain range: TCWVF, surface temperature, relative humidity at $950 \mathrm{hPa}$ and wind speed and sector. The level of $950 \mathrm{hPa}$ has been chosen since it is the average pressure level of the plateau.
Figure 8 shows box plot diagrams for relative humidity at $950 \mathrm{hPa}$ (the rest of plot diagrams are not shown). These box plots are a common tool useful to detect different populations in a sample using null hypothesis contrast from the median and the interquartile values since both parameters are robust towards the presence of outliers. Two groups of data have been considered per site and season: wet (W) and dry (D). Then, the extremes, the upper and lower hinges (quartiles), and the median have been calculated and used for the box plot. On each box, the central mark is the median, the edges of the box are the 25th $\left(q_{1}\right)$ and 75th $\left(q_{3}\right)$ percentiles, the whiskers extend to the most extreme data points not considered outliers, and outliers are plotted individually. Points are drawn as outliers if they are larger than $q_{3}+1.5\left(q_{3}-q_{1}\right)$ or smaller than $q_{1}-1.5\left(q_{3}-q_{1}\right)$. The value of 1.5 corresponds to approximately $\pm 2.7 \sigma$ (being $\sigma$ the standard deviation) and 99.3 coverage if the data are normally distributed. The plotted whisker extends to the adjacent value, which is the most extreme data value that is not an outlier. The two medians, corresponding wet and dry day populations, are considered significantly different at the $5 \%$ significance level if their intervals, defined by the notches, do not overlap. In that case, true medians do differ with $95 \%$ confidence. Applying the notches comparison graphically is like applying a $t$-test with the upper and lower limits that fulfil the frequency distribution for the significance level (McGill et al., 1978). Figure 8 shows box plot for relative humidity, where left box corresponds to wet days and right box to dry days. From this figure seems easy to infer that the two populations (wet and dry events) are significantly different, since the notches do not overlap. Similar results are obtained for the rest of variables such relative humidity at low levels, surface temperature and wind (not shown). 
Table IV. Significant medians of ERA-interim variables closely related to orographic precipitation for wet (W) and dry (D) days at the three observatories (Bold characters for wet days).

\begin{tabular}{|c|c|c|c|c|c|c|}
\hline Season & Site & Kind & $\begin{array}{l}\text { Upwind TCWVF } \\
\left(\mathrm{kg} \mathrm{m}^{-1} \mathrm{~s}^{-1}\right)\end{array}$ & $\begin{array}{l}\text { Upwind surface } \\
\text { temperature }\left({ }^{\circ} \mathrm{C}\right)\end{array}$ & $\begin{array}{l}\text { Upwind relative humidity } \\
\text { at } 950 \mathrm{hPa}(\%)\end{array}$ & $\begin{array}{l}\text { Wind sector and speed } \\
\text { at } 850 \mathrm{hPa}\left(\mathrm{m} \mathrm{s}^{-1}\right)\end{array}$ \\
\hline \multirow[t]{6}{*}{ Winter } & $\mathrm{S}$ & W & 165 & 6 & 86 & W (6.16) \\
\hline & & D & 69 & 5 & 76 & $\mathrm{~N}(1.1)$ \\
\hline & $\mathrm{N}$ & W & 152 & 6 & 84 & W (4.9) \\
\hline & & $\mathrm{D}$ & 60 & 5 & 75 & $\mathrm{~N}(1.26)$ \\
\hline & $\mathrm{C}$ & W & 165 & 6 & 86 & SW (6.0) \\
\hline & & D & 71 & 5 & 76 & $\mathrm{~W}(1.6)$ \\
\hline \multirow[t]{6}{*}{ Spring } & $\mathrm{S}$ & W & 141 & 11 & 71 & W (4.15) \\
\hline & & $\mathrm{D}$ & 78 & 12 & 55 & SW $(0.7)$ \\
\hline & $\mathrm{N}$ & W & 135 & 11 & 69 & W (3.74) \\
\hline & & $\mathrm{D}$ & 73 & 13 & 54 & $\mathrm{~N}(0.8)$ \\
\hline & $\mathrm{C}$ & W & 144 & 11 & 72 & SW (4.14) \\
\hline & & $\mathrm{D}$ & 80 & 13 & 56 & NW (1.1) \\
\hline \multirow{6}{*}{ Summer } & $\mathrm{S}$ & W & 143 & 21 & 49 & SW (2.5) \\
\hline & & D & 100 & 24 & 38 & W (1.1) \\
\hline & $\mathrm{N}$ & W & 139 & 21 & 49 & SW $(2.3)$ \\
\hline & & $\mathrm{D}$ & 100 & 24 & 38 & $\mathrm{~W}(1.2)$ \\
\hline & $\mathrm{C}$ & W & 142 & 21 & 49 & SW(2.2) \\
\hline & & $\mathrm{D}$ & 102 & 24 & 38 & $\mathrm{~W}(1.3)$ \\
\hline \multirow[t]{6}{*}{ Fall } & $\mathrm{S}$ & W & 199 & 12 & 76 & W (5.7) \\
\hline & & D & 95 & 15 & 59 & NW (0.6) \\
\hline & $\mathrm{N}$ & W & 190 & 12 & 75 & SW (5.0) \\
\hline & & D & 87 & 15 & 58 & $\mathrm{~N}(0.66)$ \\
\hline & $\mathrm{C}$ & W & 206 & 13 & 77 & SW (5.9) \\
\hline & & $\mathrm{D}$ & 99 & 14 & 60 & NW (1.16) \\
\hline
\end{tabular}

Table IV summarizes the results obtained for every site and season. This table summarizes the mean conditions of the main variables found in the air masses that reach CS and lead to precipitation (for wet days). As expected, precipitation at the CS seems to be very related with advection of air masses transporting moisture from the Atlantic as seen in the significant different values of TCWVF for wet and dry days. This points out orographic precipitation as the main phenomena in CS precipitation. This is confirmed by the differences found in the relative humidity of air advecting at $950 \mathrm{hPa}$ for wet and dry days, specially during fall. Relative humidity is a very sensitive variable for orographic precipitation models, specially for low TCWVF (Barstad et al., 2007). Relating wind direction, it is remarkable how mean sector for wet days at site $\mathrm{S}$ is always W except in summer. On the other hand, mean $850 \mathrm{hPa}$ wind sector for wet days at $\mathrm{C}$ is always SW. The simplicity of this classification scheme makes robust the idea of precipitation at the CS being highly dependent on wind direction at medium levels of the troposphere.

To illustrate the directional dependency of precipitation at SC, Figure 9 shows rain-roses for the four seasons and the three sites. Here, wind direction is divided in eight sectors containing three filled sectors representing accumulated precipitation at each observatory. These graphs are useful since they show the relationship between wind direction and total mean precipitation. Mostly of the precipitation at the three observatories come from 'sector SW', nevertheless 'sector W' is relevant for S while 'sector $S$ ' is relevant for C. Taking into account the orientation of the axis of SC (Figure 1(b)), a rain shadow effect might be the cause of differences between different sides of the range. Again, it seems like site $\mathrm{N}$ shares behaviour of both sides and is less wind direction dependent. The mountain range would be drying the air masses that travel from the Atlantic inland, sometimes these air masses have a more west component giving precipitation at the windward side of the mountain, in this case the northern side, and the top of the range; and sometimes with a more south component giving precipitation at the southern side and top.

These results reinforces the need of a combination of tools, modelling and high density measurements, if a reliable assessment of precipitation is wanted for such complex orography. Specific orographic precipitation models are very convenient in these cases since they allow the use of higher spatial resolutions, consideration of more complex precipitation phenomena and longer time domains with many resolution (Barstad et al., 2008). These models are sensible to boundary conditions and respond differently to changes in wind speed and direction, relative humidity, surface temperature and other variables related with orographic precipitation. It has been shown here that ERA-Interim boundary conditions could be acceptable for such purpose.

\section{Conclusions}

Even though numerous studies about precipitation regimes, climate variability, regionalization and other 

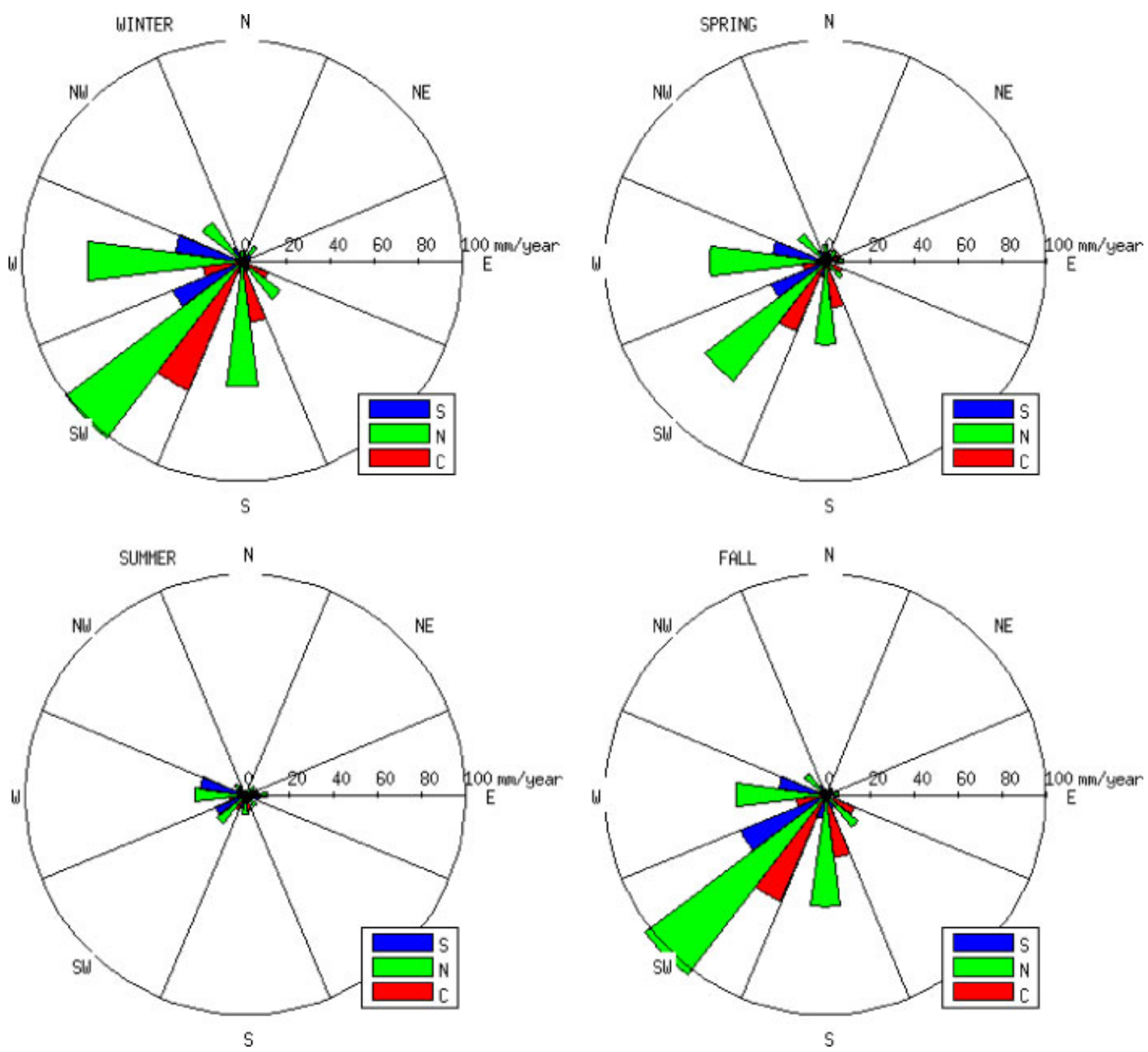

Figure 9. Rain-roses for the four seasons. Grey shaded sectors represent seasonally accumulated rain for $850 \mathrm{hPa}$ wind coming from each sector.

climate analysis can be found focused in Western Europe and the IP for last decades, not much has been found about precipitation climatology in the CS mountain range.

A basic climatic analysis has shown significant differences between top, northern and southern regarding total precipitation, inter annual variability and time of summer drought. Solid precipitation amounts at the top of mountain are comparable with liquid precipitation during winter, spring and fall.

Despite the small distance among the three sites, only half of the rain episodes occur simultaneously at all of them, pointing out the complexity of the spatial distribution of precipitation.

Total column water vapour flux calculated out of ERA Interim reanalysis has shown to be a reliable field to understand the influence of synoptic forcings on precipitation at the mountain range.

It has been shown how CS, although is located at a considerable distance inland and surrounded by two extensive plateaus, is under the direct influence of the humid air masses coming from the Atlantic Ocean. Its presence generates the well-known drying effect of a mountainous region, acting as a moisture sink of the air masses that cross the IP. This results also indicate the small importance of local convective processes on the total precipitation.

It has been found that precipitation is strongly direction-dependent. The relative position of the range axis is crucial. This can be clearly seen as half of wet days, precipitation can happen at one side of the range and top, or the other side, indicating fragmented spatial patterns due to orography. This is also probably the reason of the summer drought shift found between northern and southern side.

Data from the observatories used here could be an excellent foundation for building a reliable climatic assessment of precipitation in the CS. To have a better picture of precipitation at CS than those presented here, a combination of more observations and models is required. Due to the main precipitation phenomena found in the area, specific orographic precipitation models seem to be the most adequate, along with new measurements that could be able to account for all forms of precipitation. 


\section{Acknowledgements}

The authors would like to thank the European Centre for Medium-Range Weather Forecasts (ECMWF) for providing the ERA-Interim Data and the Agencia Estatal de Meteorología (AEMET) for providing the observational data.

\section{References}

AEMET Spanish Meteorological Service. 2011. Iberian climate atlas. http://www.aemet.es/documentos/es/divulgacion/ publicaciones/Atlas-climatologico/Atlas.pdf

Alexandersson H. 1986. A homogeneity test applied to precipitation data. International Journal of Climatology 6: 661-675.

Andres M, Tomas C, de Pablo F. 2000. Spatial patterns of the daily nonconvective rainfall in Castilla y Leon (Spain). International Journal of Climatology 20: 1207-1224.

Arribas A, Gallardo C, Gaertner M, Castro M. 2003. Sensitivity of the Iberian Peninsula to a land degradation. Climate Dynamics 20: 477-489.

Barstad I, Smith RB. 2005. Evaluation of an orographic precipitation model. Journal of Hydrometeorology 6: 85-99.

Barstad I, Grabowski WW, Smolarkiewicz PK. 2007. Characteristics of large-scale orographic precipitation: evaluation of linear model in idealized problems. Journal of Hydrology. 340: 78-90.

Barstad I, Sorteberg A, Flatøy F, Déqué M. 2008. Precipitation, temperature and wind in Norway: dynamical downscaling of ERA40. Climate Dynamics 33(6): 769-776.

Beranova R, Huth R. 2008. Time variations of the effects of circulation variability modes on European temperature and precipitation in winter. International Journal of Climatology 28: 139-158.

Beniston M. 2003. Climatic change in mountain regions: a review of possible impacts. Climatic Change 59: 5-31.

Bosch J, Carrascal LM, Durán L, Walker S, Fisher MC. 2007. Climate change and outbreaks of amphibian chytridiomycosis in a montane area of Central Spain; is there a link? Proceedings of the Royal Society B: Biological Sciences 274: 253-260.

Bougeault P, Binder P, Buzzi A, Dirks R, Houze R, Kuettner J, Smith RB, Steinacker R, Volkert H. 2001. The MAP special observing period. Bulletin of the American Meterological Society $\mathbf{8 2}$ : $433-462$.

Briggs PR, Cogley JG. 1996. Topographic bias in mesoscale precipitation networks. Journal of Climate 9: 205-218.

Chen M, Shi W, Xie P, Silva V, Kousky V, Higgins RW, Janowiak K. 2008. Assessing objective techniques for gauge-based analyses of global daily precipitation. Journal of Geophysical Research 113: D04110.

Daly C, Neilson RP, Phillips DL. 1994. A statistical-topographic model for mapping climatological precipitation over mountainous terrain. Journal of Applied Meteorology 33: 140-158.

Del Río S, Herrero L, Fraile R, Penas A. 2010. Spatial distribution of recent rainfall trends in Spain (1961-2006). International Journal of Climatology 31: 656-667.

Durán L. 2003. Description and preliminary results of a Meteorological Network for High Altitudes. EGS-AGU-EUG Joint Assembly. Geophysical Research Abstracts 5: 12466.

Esteban-Parra MJ, Rodrigo FS, Castro Díez Y. 1998. Spatial and temporal patterns of precipitation in Spain for the period 1880-1992. International Journal of Climatology 18: 1557-1574.

Fernandez-Mills G. 1995. Principal component analysis of precipitation and rainfall regionalization in Spain. Theoretical and Applied Climatology 50: 169-183.

Font-Tullot I. 1983. Climatología de España y Portugal. Instituto Nacional de Meteorología: Madrid.

Frei C, Schär C. 1998. A precipitation climatology of the Alps from high-resolution rain-gauge observations. International Journal of Climatology 18: 873-900.

Gavilán R, Fernández F, Blasi C. 1998. Climatic classification and ordination of the Spanish Sistema Central; relationships with potential vegetation. Plant Ecology 139: 1-11.

Gallego MC, García JA, Vaquero JM. 2005. The NAO signal in daily rainfall series over the Iberian Peninsula. Climate Research 29: $103-109$.
García-Marín AP, Ayuso-Muñoz JL, Taguas-Ruiz EV, Estevez J. 2011. Regional analysis of the annual maximum daily rainfall in the province of Malaga (southern Spain) using the principal component analysis. Water and Environment Journal 25: $522-531$.

García-Romero A, Muñoz J, Andrés N, Palacios D. 2010. Relationship between climate change and vegetation distribution in the Mediterranean mountains: Manzanares Head valley, Sierra De Guadarrama (Central Spain). Climatic Change 100: 645-666.

González-Rouco JF, Jimenez JL, Quesada V, Valero F. 2001. Quality control and homogeneity of precipitation data in the Southwest of Europe. Journal of Climate 14: 964-978.

Goodess CM, Jones PD. 2002. Links between circulation and changes in the characteristics of Iberian rainfall. International Journal of Climatology 22: 1593-1615.

Goovaerts P. 2000. Geostatistical approaches for incorporating elevation into the spatial interpolation of rainfall. Journal of Hydrology 228: $113-129$.

Guan H, Wilson JL, Makhnin O. 2005. Geostatistical mapping of mountain precipitation incorporating autosearched effects of terrain and climatic characteristics. Journal of Hydrometeorology $\mathbf{6}$ : 1018-1031.

Haylock MR, Hofstra N, Klein Tank AMG, Klok EJ, Jones PD, New M. 2008. A European daily high-resolution gridded data set of surface temperature and precipitation for 1950-2006. Journal of Geophysical Research 113: D20119.

Herrera S, Fita L, Fernández J, Gutiérrez JM. 2010. Evaluation of the mean and extreme precipitation regimes from the ENSEMBLES regional climate multimodel simulations over Spain. Journal of Geophysical Research 115: D21117, DOI: 10.1029/2010JD013936

Herrera S, Gutiérrez JM, Ancell R, Pons MR, Frías MD, Fernández J. 2012. Development and analysis of a 50-year high-resolution daily gridded precipitation dataset over Spain (Spain02). International Journal of Climatology 32: 74-85, DOI: 10.1002/joc.2256.

Jacob D, Bärring L, Christensen OB, Christensen JH, de Castro M, Deque M, Giorgi F, Hagemann S, Hirschi M, Jones R, Kjellström E, Lenderink G, Rockel B, Sanchez E, Schär C, Seneviratne SI, Somot S, van Ulden A, van den Hurk B. 2007. An inter-comparison of regional climate models for Europe: model performance in presentday climate. Climatic Change 81: 31-52.

Kirshbaum DJ, Smith RB. 2008. Temperature and moist-stability effects on midlatitude orographic precipitation. Quarterly Journal of the Royal Meteorological Society 134: 1183-1199 Part A.

Kyriakidis PC, Kim J, Miller NL. 2001. Geostatistical mapping of precipitation from rain gauge data using atmospheric and terrain characteristics. Journal of the Applied Meteorology 40: 1855-1877.

Lawford R, Stewart J, Roads H-J, Isemer M, Manton J, Marengo T, Yasunari S, Benedict TK, Williams S. 2004. Advancing Global and continental-scale hydrometeorology. Contributions of GEWEX Hydrometeorology Panel. Bulletin of the American Meterological Society 85: 1917-1930, DOI: 10.1175/BAMS-85-12-1917

Lawford RG, Roads J, Lettenmaier DP, Arkin P. 2007. GEWEX contributions to large-scale hydrometeorology. Journal of Hydrometeorology 8: 629-641.

Little MA, Rodda HJE, McSharry PE. 2008. Bayesian objective classification of extreme UK daily rainfall for flood risk applications. Hydrology and Earth System Sciences, Discussion. 5: 3033-3060.

Lo Y-H, Blanco JA, Seely B, Welham C, Kimmins JP. 2011. Generating reliable meteorological data in mountainous areas with scarce presence of weather records: the performance of MTCLIM in interior British Columbia, Canada. Environmental Modelling and Software 26(5): 644-657, DOI: 10.1016/j.envsoft.2010.11.005

López-Bustins JA, Martín-Vide J, Sánchez-Lorenzo A. 2008. Iberia winter rainfall trends based upon changes in teleconnection and circulation patterns. Global and Planetary Change 63(2-3): $171-176$.

López-Moreno JI, Beniston M, García-Ruiz JM. 2008. Environmental change and water management in the Pyrenees: facts and future perspectives for Mediterranean mountains. Global and Planetary Change 61: 300-312.

López-Moreno JL, Vicente Serrano SM, Morán-Tejeda E, LorenzoLacruz J, Kenawy A, Beniston B. 2011. Effects of the North Atlantic Oscillation (NAO) on combined temperature and precipitation winter modes in the Mediterranean mountains: Observed relationships and projections for the 21st century. Global and Planetary Change 77: $62-76$.

Losada T, Rodríguez-Fonseca B, Garcia-Serrano J, Mechoso CR. 2007. Impacts of SST Anomalies on the North Atlantic Atmospheric 
Circulation: A case study for the Northern Winter 1995/96. Climate Dynamics 29: 807-819.

Mariotti A, Struglia MV. 2002. The hydrological cycle in the Mediterranean region and implications for the water budget of the Mediterranean sea. Journal of Climate 15: 1674-1690.

Marquínez J, Lastra J, García P. 2003. Estimation models for precipitation in mountainous regions: the use of GIS and multivariate analysis. Journal of Hydrology 270: 1-11.

Martín-Vide J. 2004. Spatial distribution of a daily precipitation concentration index in peninsular Spain. International Journal of Climatology 24: 959-971.

Matsuura K. and Willmott C. J. 2009 Terrestrial Air Temperature: 1900-2008 Gridded Monthly Time Series. Center for Climatic Research, Dep. Of Geography, University of Delaware, Newark. http://climate.geog.udel.edu/ climate/

McGill R, Tukey JW, Larsen WA. 1978. Variations of Boxplots. The American Statistician 32(1): 12-16.

Muñoz-Díaz D, Rodrigo FS. 2004. Impacts of the North Atlantic Oscillation on the probability of dry and wet winters in Spain. Climate Research 27: 33-43.

New M, Hulme M, Jones PD. 1999. Representing twentieth century space-time climate variability, 1, Development of a 1961-90 mean monthly terrestrial climatology. Journal of Climate $\mathbf{1 2}$ 829-856.

Nystuen JA. 1999. Relative performance of automatic rain gauges under different rainfall conditions. Journal of Atmospheric and Oceanic Technology 16: 1025-1043.

Paredes D, Trigo RM, Garcia-Herrera R, Trigo IF. 2006. Understanding precipitation changes in Iberia in early spring: weather typing and storm-tracking approaches. Journal of Hydrometeorology 7(1): $101-113$.

Rasmuson EM. 1968. Atmospheric water vapor transport and the water balance of North America. Monthly Weather Review 96: 720-734.

Rodríguez-Fonseca B, Castro M. 2002. On the connection between winter anomalous precipitation in the Iberian Peninsula and Morocco and the summer subtropical Atlantic SST. Geophysical Research Letters 29: 1863-1866.

Rodríguez-Fonseca B, Serrano E. 2002. Winter 10-day coupled patterns between geopotential height and Iberian Peninsula rainfal using the ECMWF precipitation reanalysis. Journal of Climate 15: $1309-1321$.

Rodríguez-Fonseca B, Polo I, Serrano E, Castro M. 2006. Evaluation of the North Atlantic SST forcing on the European and northern African winter climate. International Journal of Climatology 26: 179-191.
Rodriguez-Puebla C, Encinas AH, Nieto S, Garmendia J. 1998. Spatial and temporal patterns of annual precipitation variability over the Iberian Peninsula. International Journal of Climatology 18 : 299-316.

Roe GH. 2005. Orographic precipitation. Annual Review of Earth and Planetary Sciences 33: 645-71.

Romero R, Ramis C, Guijarro JA, Sumner G. 1999. Daily rainfall affinity areas in the Mediterranean Spain. International Journal of Climatology 19: 557-578.

Smith RB, Barstad I. 2004. A linear theory of orographic precipitation. Journal of the Atmospheric Sciences 61(12): 1377-1391.

Sánchez E, Domínguez M, Romera R, de la Franca NL, Gaertner M, Gallardo C, Castro M. 2011. Regional modeling of dry spells over the Iberian Peninsula for present climate and climate change conditions. Climatic Change 107: 625-634.

Serrano A, García JA, Mateos VL, Cancillo ML, Garrido J. 1999. Monthly modes of variation of precipitation over the Iberian Peninsula. Journal of Climate 12: 2894-2919.

Sevruk B. 1996. Adjustment of tipping-bucket precipitation gauge measurements. Atmospheric Research 42(1-4): 237-246.

Trenberth KE, Guillemot CJ. 1998. Evaluation of the atmospheric moisture and hydrological cycle in the NCEP/NCAR reanalyses. Climate Dynamics 14: 213-231.

Trigo RM, Palutikof JP. 2001. Precipitation scenarios over Iberia: a comparison between direct GCM output and different downscaling techniques. Journal of Climate 14: 4422-4446.

Trigo RM, Pozo-Vázquez D, Osborn TJ, Castro-Díez Y, Gámiz-Fortis S, Esteban-Parra MJ. 2004. North Atlantic oscillation influence on precipitation, river flow and water resources in the Iberian Peninsula. International Journal of Climatology 24: 925-944.

Uppala SM, Dee DP, Kobayashi S, Berrisford P, Simmons AJ. 2008. Towards a climate data assimilation system: Status update of ERAInterim. ECMWF Newsletter 115: 12-18.

WMO World Meteorological Organization 2008. Guide to Meteorological Instruments and Methods of Observation. WMO-No. 8. 7. Meteorological Organization, 978-92-63-100085.

Zanchettin D, Franks SW, Traverso P, Tomasino M. 2008. On ENSO impacts on European wintertime rainfalls and their modulation by the NAO and the Pacific multi-decadal variability described through the PDO index. International Journal of Climatology 28(8): 995-1006. Zorita E, Kharin V, von Storch H. 1992. The atmospheric circulation and sea surface temperature in the North Atlantic Area in winter: their interaction and relevance for Iberian precipitation. Journal of Climate 5: 1097-1108. 